\title{
Editorial
}

\section{Public health: someone must have been doing something right!}

After two editorials ${ }^{(1,2)}$ pointing out the importance of rapid, forceful and sustained action to decrease rates of malnutrition globally, the editors find it important to point to some positive developments in the last 50 to 100 years. The current situation is harsh and difficult, but we have shown previously that it is possible to make a difference.

\section{Infant mortality rates have gone down drastically}

Table 1 illustrates the change in infant mortality rates, according to WHO statistics. Across a wide geographic and economic range, many countries have made substantial progress, partly due to improvements in sanitation and control of infectious diseases but also due to an improved nutritional situation. Even within a country with a comparatively low infant mortality rate in 1960 like Sweden, the infant mortality rate can be pushed down even further by a conscious policy to invest in a highquality Mother and Child Health Care programme. Apparently someone is doing something right.

\section{We live longer}

Life expectancy at birth (Table 2) has also shown some dramatic improvements, of course due largely to the decline in infant mortality rates shown in Table 1.

In richer countries we can see the dramatic improvements occurring early in the 20th century, but we can identify major improvements in low-income countries as well. Overall, when looking at the change in life expectancy from 1880 to 2007, we find that, as for infant mortality, a broad geographic and economic representation of countries has improved immensely. The increase is between 33 and 49 years longer life expectancy in 2007, except for the two African countries where the change in life expectancy is much lower, 17 and 24 years. The biggest change has happened in Costa Rica an increase in life expectancy from 30 to 79 years between 1880 and 2007. Notably, Sweden has also made progress during the last 50 years - an increase in life expectancy from 73 to 81 years between 1960 and 2007 - which means that the massive immigration to the country has not resulted in any adverse impact on these health indicators.

\section{Three wise men}

We end the editorial, and the year, with some concepts and words from three wise men.

\section{Wise man \#1: Professor Hans Rosling, on the importance of illustrating change}

If you wish to illustrate health changes over time, in teaching or lecturing, data are very nicely put to life by using the Gapminder World software (http://gapminder.org), produced for free access by Professor Hans Rosling of the Karolinska Institute. Using Gapminder World, you can see the changes in infant mortality rates, life expectancy and many other social, economic and health indicators over time between countries and depending on country size. It becomes very obvious which countries have made good progress and which have not, a powerful tool in internal politics as well as foreign affairs.

\section{Wise man \#2: Professor Leif Hambraeus, on the importance of an enlightened leadership}

Professor Leif Hambraeus of the Karolinska Institute comments: 'It took 20 years for Costa Rica to increase life expectancy from 47 to 62 years (1940-60) but 40 years for Sweden from 44 to 61 (NB 1880-1920) and also 40 years

Table 1 Infant mortality rates per 1000 births in selected countries, 1960-2006

\begin{tabular}{lrrrrr}
\hline & 1960 & 1997 & 2000 & 2005 & 2006 \\
\hline Mali & 293 & 145 & 124 & 120 & 119 \\
Ethiopia & 175 & 111 & 92 & 80 & 77 \\
Guatemala & 137 & 43 & 39 & 32 & 31 \\
China & 140 & 38 & 26 & 21 & 22 \\
India & 95 & 63 & 63 & 59 & 57 \\
Costa Rica & 80 & 12 & 13 & 11 & 11 \\
Sweden & 16 & 4 & 3 & 3 & 3 \\
\hline
\end{tabular}

Table 2 Life expectancy at birth (years) in selected countries, 1880-2007

\begin{tabular}{lccccccccc}
\hline & 1880 & 1900 & 1920 & 1940 & 1960 & 1980 & 2000 & 2002 & 2007 \\
\hline Bangladesh & 26 & 22 & 24 & 32 & 40 & 63 & 70 & 62 & 62 \\
Brazil & 32 & 32 & 32 & 36 & 55 & 63 & 70 & 71 & 72 \\
China & 32 & 32 & 32 & 36 & 32 & 66 & 71 & 72 & 73 \\
Costa Rica & 30 & 35 & 36 & 47 & 62 & 72 & 78 & 78 & 79 \\
Cuba & 36 & 33 & 38 & & 64 & 73 & 77 & 77 & 78 \\
Denmark & 45 & 52 & 62 & 66 & 72 & 74 & 77 & 77 & 78 \\
India & 25 & 24 & 25 & 32 & 42 & 56 & 62 & 63 & 65 \\
Indonesia & 33 & 33 & 33 & 31 & 41 & 55 & 68 & 69 & 71 \\
Japan & 36 & 39 & 42 & 39 & 68 & 76 & 81 & 82 & 83 \\
Kenya & 29 & 26 & & 27 & 47 & 58 & 52 & 51 & 54 \\
Nigeria & 30 & 30 & 30 & 30 & 39 & 45 & 47 & 47 & 47 \\
Sweden & 44 & 52 & 61 & 67 & 73 & 76 & 80 & 80 & 81 \\
Thailand & 30 & 30 & 30 & 39 & 55 & 64 & 68 & 69 & 71 \\
USA & 39 & 49 & 55 & 63 & 70 & 74 & 77 & 77 & 78 \\
\hline
\end{tabular}


for India with 1 billion inhabitants from 42 to 62 (19602000)! It must be seen as a miracle that India has increased the life expectancy with 40 years over these last 127 years. India is after all a federation of states of 1 billion inhabitants altogether! India has a free press and a democratic system that apparently works in promoting health, even though differences within India are obviously vast. We can ask ourselves also to what extent corruption corrodes the results for some countries, and how a strong political leadership run by an enlightened government can lead a country through difficulties towards a healthier life'.

\section{Wise man \#3: Ban Ki-Moon, on the importance of mobilizing}

'There is more than enough food in the world, yet today, over one billion people are hungry', said Ban Ki-Moon at a follow-up meeting of the G8 meeting in Italy last week. 'This is unacceptable. [...] Ever more people are denied the food they need because prices are stubbornly high, because their purchasing power has fallen due to the economic crisis, or because rains have failed and reserve stocks of grain have been eaten. [...] Now is the time to demonstrate to food-insecure nations and communities that we want to [...] develop a roadmap for action and secure tangible results' ${ }^{(3)}$. Representatives from twentysix countries and several international organisations met at the G8 meeting in July and promised more than \$US 20 billion for coordinated and sustainable action against hunger - a show of support to address underlying causes of food insecurity.

Forceful action is required. To achieve dramatic improvements in health, we need political systems that put health first, and tools and strategies to mobilize organizations and people into action. History shows us that it is possible.

\author{
Agneta Yngve \\ Barrie Margetts \\ Roger Hughes \\ Marilyn Tseng \\ Editor-in-Chief and Deputy Editors \\ Public Health Nutrition
}

\section{References}

1. Yngve A, Margetts B, Hughes R et al. (2009) Editorial on the occasion of the International Congress of Nutrition. World hunger: a good fight or a losing cause? (Editorial). Public Health Nutr 12, 1685-1686.

2. Yngve A, Margetts B, Hughes R et al. (2009) Food insecurity - not just about rural communities in Africa and Asia (Editorial). Public Health Nutr 12, 1971-1972.

3. UN News Centre (2009) Global food security takes centre stage at high-level UN event. http://www.un.org/apps/ news/story.asp?NewsID $=32293 \& \mathrm{Cr}=$ food + crisis $\& C r 1$ (accessed October 2009). 